\title{
Como compatibilizar conservação, desenvolvimento e turismo: a experiência do Baixo Rio Negro, Amazonas
}

\section{Nailza Pereira Souza, Sherre Prince Nelson, José Eduardo Lozano Badialli, Marco Antônio Vaz de Lima, Suzana Machado Padua}

\section{RESUMO}

Este artigo aborda os passos realizados para o ordenamento da atividade turística no baixo Rio Negro do Estado do Amazonas, tornando-o mais sustentável por envolver representantes dos segmentos sociais, incluindo comunidades, guias, donos de barcos, operadores, ONGs e entidades governamentais de turismo e meio ambiente, e também por ampliar o conhecimento destes protagonistas em relação à biodiversidade local. Infelizmente, ao longo das últimas décadas, os envolvidos nesta atividade tiveram muitas dificuldades para interagir, o que levou a práticas isoladas. Apesar do fato de o baixo rio Negro ser composto por um mosaico de Unidades de Conservação federais, estaduais e municipais, muitos dos protagonistas locais não estavam cientes disto, nem tampouco dos potenciais que estas áreas podem representar para o turismo, de acordo com suas respectivas categorias de manejo. O IPÉ- Instituto de Pesquisas Ecológicas, uma organização sem fins lucrativos que por mais de uma década atua na região em programas socioambientais, começou, no ano de 2002, a promover diálogos entre os diferentes setores e membros das comunidades regionais, com o intuito de re-direcionar este quadro para uma atividade mais sustentável. O IPÉ parte do pressuposto que o tema turismo e meio ambiente no baixo Rio Negro, como em muitos outros lugares, precisa ser trabalhado de maneira integrada. O êxito do turismo depende de um meio ambiente conservado onde fundos derivados desta atividade econômica devam ser aplicados tanto para a conservação como também para promover benefícios diretos para as comunidades locais. Oficinas e cursos estão sendo realizados com a participação de representantes de todos os segmentos sociais e os resultados iniciais indicam eficácia. Percebeu-se a melhoria das habilidades de interpretação ambiental, que ampliou o conhecimento dos guias e os níveis de empenho, além de iniciativas de lideranças comunitárias para desenvolver produtos sustentáveis. Este projeto está em fase de execução e seus resultados iniciais demonstram que é possível através de educação e integração dos protagonistas buscar uma atividade turística mais responsável e sustentável sob o ponto de vista socioambiental.

PALAVRAS-CHAVE: Meio Ambiente, Turismo Sustentável, Ordenamento da Atividade Turística 


\section{How to reconcile conservation, tourism and development: the experience of the lower Rio Negro, Amazonas, Brazil}

\section{ABSTRACT}

This article addresses the steps taken to improve tourism in the lower Negro River basin in the State of Amazonas, making it more sustainable by involving all stakeholders including local communities, guides, boat owners, tour operators, NGOs and representatives from both tourism and environmental government entities at federal, state and municipal levels, as well as increasing their knowledge of the local biodiversity. Unfortunately, over the last few decades some of these stakeholders had a difficult time interacting with each other. Despite the fact that the lower Negro River is comprised of a mosaic of federal, state and municipal protected areas, many of the stakeholders were not aware of their existence, nor what activities are possible in each of the different categories of the protected areas. In 2002 Institute for Ecological Research (IPE), a non-governmental organization that has been promoting socioenvironmental programs in the region for more than a decade, initiated dialogues between the tourism sector and the various stakeholders with the aim of directing it towards a more sustainable activity. IPÉ's team understands that tourism and environment in the lower rio Negro basin, as in many other places, need to be dealt in an integrated manner. The success of tourism depends upon a pristine environment where funds derived from this economic activity are applied towards conservation as well as directly benefiting local communities. Workshops and courses are held with the participation of different stakeholders and initial results are encouraging, including improvement of environmental interpretation skills, which have enhanced the guides knowledge and performance levels; community leadership initiatives have improved and several sustainable products have been development. This project is ongoing and the initial results have shown that through education and stakeholder integration, the common goal of conserving the environment while benefiting local communities by encouraging sustainable tourism can be attained.

Key words: Environment, Sustainable Tourism, Tourism Planning.

\section{Introdução}

Na bacia amazônica estão localizados alguns dos maiores rios do mundo. Dentre eles se destaca o rio Negro, afluente do rio Amazonas, que apresenta rica biodiversidade e grande beleza cênica. $O$ trecho final de sua extensa bacia que vai do município de Novo Airão até a capital do Estado, Manaus, é chamado de "baixo rio Negro". Esta região está inserida no Corredor Ecológico Central da Amazônia, maior área de proteção ambiental contínua do mundo. A importância ecológica e social dos ecossistemas do baixo rio Negro é evidenciada pela grande diversidade biológica o que lhe confere a classe de área de extrema importância para conservação, segundo o Relatório "Biodiversidade Brasileira" (BRASIL, 2002). Em 2003, a então Estação E- 
cológica (ESEC) de Anavilhanas, atualmente Parque Nacional de Anavilhanas, foi declarada Sítio do Patrimônio Natural da Humanidade pela UNESCO. Além desta unidade de conservação, a região do baixo rio Negro é composta por um mosaico de mais sete áreas protegidas.

Em 1997, pesquisadores do IPÊ - Instituto de Pesquisas Ecológicas ${ }^{1}$ coordenaram a elaboração do Plano de Manejo da Estação Ecológica de Anavilhanas, juntamente com outras instituições de pesquisa da região. A experiência foi fundamental para o conhecimento do bioma amazônico e das populações ribeirinhas residentes. Logo depois, no ano 2000, o IPÊ iniciou seus trabalhos na região, mais especificamente no baixo Rio Negro. Em 2002, celebrou um termo de cooperação técnica com o Instituto Brasileiro do Meio Ambiente e de Recursos Naturais (IBAMA) para desenvolver trabalhos de pesquisa na ESEC de Anavilhanas e sua área de influência, envolvendo ações com espécies ameaçadas de extinção, educação ambiental e alternativa de desenvolvimento sustentável para comunidades ribeirinhas. Uma dessas alternativas é o turismo em bases sustentáveis.

O rio Negro apresenta grande beleza cênica, água de cor escura, praias de areia clara ao longo de suas margens e poucos insetos para incomodar os visitantes. Essas condições têm atraído turistas há anos (PEREIRA, 2007). No baixo rio Negro os primeiros alojamentos de selva foram construídos na década de 80 e, atualmente, existem mais do que oito com preços e níveis de conforto variados, além de outros sendo construídos. O número de barcos de turismo tem aumentado a cada ano, popularizando e despertando uma forma diferente de conhecer a Amazônia. Ao longo das margens do rio Negro, populações tradicionais mantêm relação direta no uso dos recursos naturais da região, baseadas em um profundo conhecimento do ambiente, em que se denota uma forte dependência para suas atividades cotidianas, tais como agricultura, extrativismo, caça e pesca.

Apesar das evidentes condições favoráveis à prática do turismo sustentável, a realidade aponta para o sentido contrário. Mesmo com a criação das áreas protegidas, verifica-se grande impacto sobre a paisagem e sobre algumas espécies nesta região devido, principalmente, à exploração madeireira e caça comercial. Percebe-se que a atividade madeireira vem ocupando o espaço das tradicionais formas de acesso, apropriação e manejo dos recursos da biodiversidade e da agrobiodiversidade. Muitos moradores afirmam que gostariam de deixar a atividade madeireira, porém, necessitam deste recurso para sustentar a família. Há interesse para trabalhar com alternativas sustentáveis, com fins de segurança alimentar e geração de renda. Entretanto, os comunitários argumentam que é preciso apoio para o desenvolvimento e implantação das mesmas.

Em geral, as atividades turísticas desenvolvidas na região são similares e com mínimo envolvimento comunitário. Em entrevistas realizadas com guias turísticos de Manaus, Pereira (2007) notou que os mesmos não utilizavam técnicas de interpretação ambiental e cultural como ferramenta de divulgação e repasse de informações conforme anteriormente verificado por Nelson e Pereira (2004). Estes profissionais sequer referiam-se às Unidades de Conservação (UCs) que estavam sendo visitadas 
e que compõem o valioso mosaico de áreas protegidas. Além disso, a grande maioria dos empreendimentos recruta seus empregados em Manaus ou em outras regiões mais distantes, e poucos recorrem às comunidades localizadas na região, e quando o fazem é para trabalho pouco qualificado e de curta duração, desprezando o conhecimento tradicional das populações que habitam a região (BADIALLI, 2003).

A possibilidade de aproveitamento das áreas protegidas para o turismo sustentável tem sido considerada, principalmente pelos gestores e formadores de políticas públicas, como uma estratégia para a conservação da biodiversidade destes locais. Segundo Dias (2008), turismo sustentável é uma atividade que não compromete a conservação dos recursos naturais sobre os quais se sustenta e que, portanto, reconhece explicitamente a necessidade de proteção do meio ambiente. Buscando sempre a manutenção de um equilíbrio entre os três eixos básicos nos quais apóia que são: suportável ecologicamente em longo prazo, viável economicamente e equitativo desde uma perspectiva ética e social para as comunidades locais.

As Unidades de Conservação localizadas no baixo rio Negro pertencem a categorias de manejo diferentes, com normas específicas para a visitação pública em seu interior. A maior dificuldade encontrada no processo do ordenamento estava relacionada à visitação de Anavilhanas, à época ainda classificada como estação ecológica, categoria de manejo extremamente restritiva à visitação pública. Além da beleza e grande procura de turistas para conhecer o complexo labirinto de 400 ilhas que forma o arquipélago das Anavilhanas, ele está localizado na calha do rio Negro, principal acesso aos municípios de Novo Airão, Barcelos, Santa Izabel do Rio Negro e São Gabriel da Cachoeira, no Norte do Amazonas, formando uma importante hidrovia. Estava estabelecido um paradoxo sem precedentes, pois uma das regiões mais belas e procuradas pelos visitantes, e que teria que ser usada pelos barcos de transporte regulares, não podia ser acessada.

Em 2003, pesquisadores do IPÊ em parceria com alguns gestores públicos das Unidades de Conservação do baixo rio Negro iniciaram um processo de ordenamento do turismo na região. Pesquisadores e gestores concordavam que era necessário encontrar uma solução que incluísse o turismo na pauta da conservação socioambiental do baixo rio Negro. Em levantamentos preliminares realizados pelos técnicos do IPE foi constatado que grande parte dos protagonistas envolvidos não tinha este conhecimento. Desta forma, estabeleceu-se que haveria necessidade de se realizar encontros com o trade turístico ${ }^{2}$, com os gestores governamentais de turismo e meio ambiente e com comunitários residentes na região, de forma a debater e trocar informações sobre o baixo Rio Negro, suas unidades de conservação, sobre o turismo realizado nesta região com o intuito de torná-lo sustentável sob os aspectos ambientais e sociais. Desde então, diversas atividades tem sido desenvolvidas em busca destes objetivos.

\section{Objetivos}

Desde o início estabeleceu-se que o principal objetivo do projeto era promover a conservação socioambiental do baixo rio Negro por meio do turismo de bases sus- 
tentáveis. Para tanto, foi necessário envolver as instituições públicas de turismo e meio ambiente, as comunidades locais, operadores de turismo e guias, num processo de ordenamento que privilegiasse a ampliação do conhecimento, o empoderamento das comunidades locais e a união deste diferentes atores. Almeja-se para o futuro que esta importante atividade econômica seja assumida pelos seus protagonistas com benefícios socioambientais evidentes.

\section{Metodologia}

Área de Estudo

Dos cerca de 4.000.000 de hectares que formam o mosaico de unidades de conservação do baixo rio Negro este trabalho tem influencia em aproximadamente 1.800.000 hectares. Estão inseridas nesta área as seguintes Unidades de Conservação: Parque Nacional (PN) de Anavilhanas; Parques Estaduais do Rio Negro (PERN) - Setores Norte e Setor Sul, Área de Proteção Ambiental (APA) Estadual da Margem Esquerda do Rio Negro - Setor Aturiá-Apuazinho e APA Estadual da Margem Direita do Rio Negro - Setor Puduari-Solimões; Reserva de Desenvolvimento Sustentável (RDS) Municipal do Tupé (Figura 1).

A área de estudo está localizada no território de três municípios amazonenses - Iranduba, Novo Airão e Manaus - dos quais dois tem suas sedes municipais como importantes pólos de turismo: Manaus e Novo Airão. Manaus é a capital do Estado do Amazonas e possui aproximadamente dois milhões de habitantes. Está localizada no sul da área do projeto e é a "porta de entrada" dos visitantes que chegam à região. Novo Airão, por sua vez, está localizada na margem direita do Rio Negro, tem população de aproximadamente 14.000 habitantes e é sede das principais Unidades de Conservação ao Norte da região.

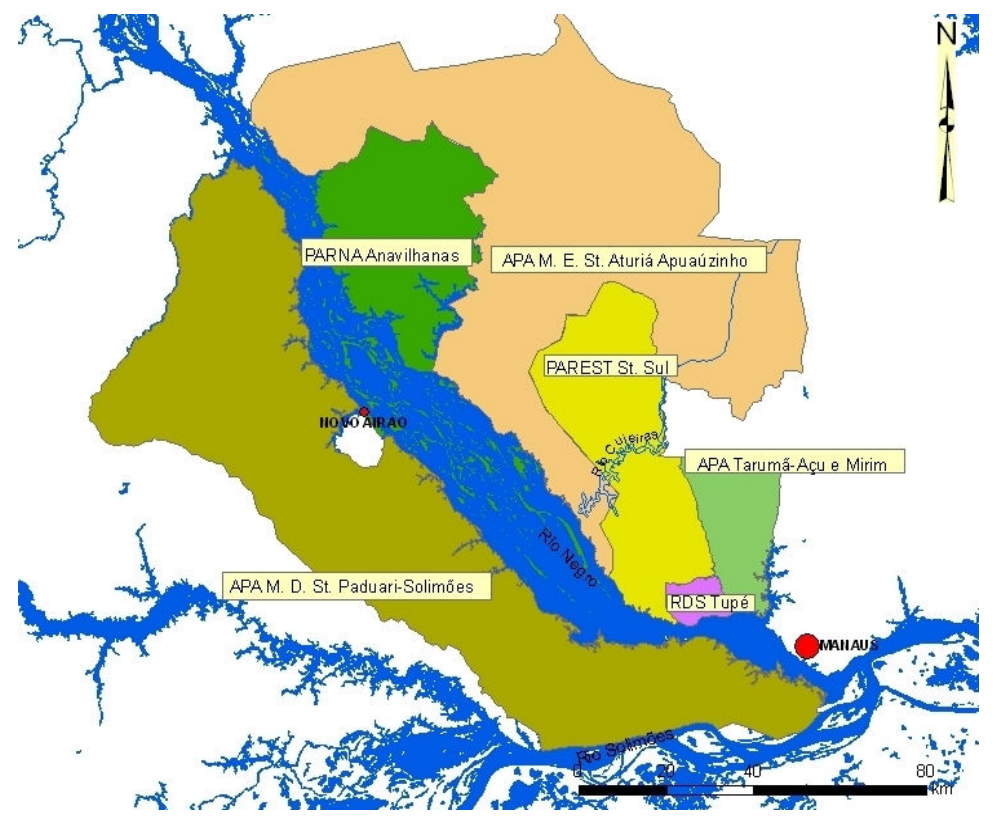

FIGURA 1: Mosaico de Unidades de Conservação do Baixo Rio Negro 
Diversas comunidades tradicionais estão localizadas nas margens do baixo rio Negro e de um de seus principais afluentes, o rio Cuieiras. Atualmente o rio Cuieiras recebe grande número de turistas, principalmente de turismo embarcado. As comunidades localizadas na região sul do entorno do Parque Nacional de Anavilhanas vêm se firmando nos últimos anos como importante pólo turístico em função de sua beleza natural, da proximidade com a zona urbana da cidade de Manaus - o que permite um rápido deslocamento dos turistas - e pelo estabelecimento de alojamentos de selva nesta região. A Figura 2 apresenta as comunidades estabelecidas nas Unidades de Conservação do baixo rio Negro que recebem visitas frequentes de turistas.

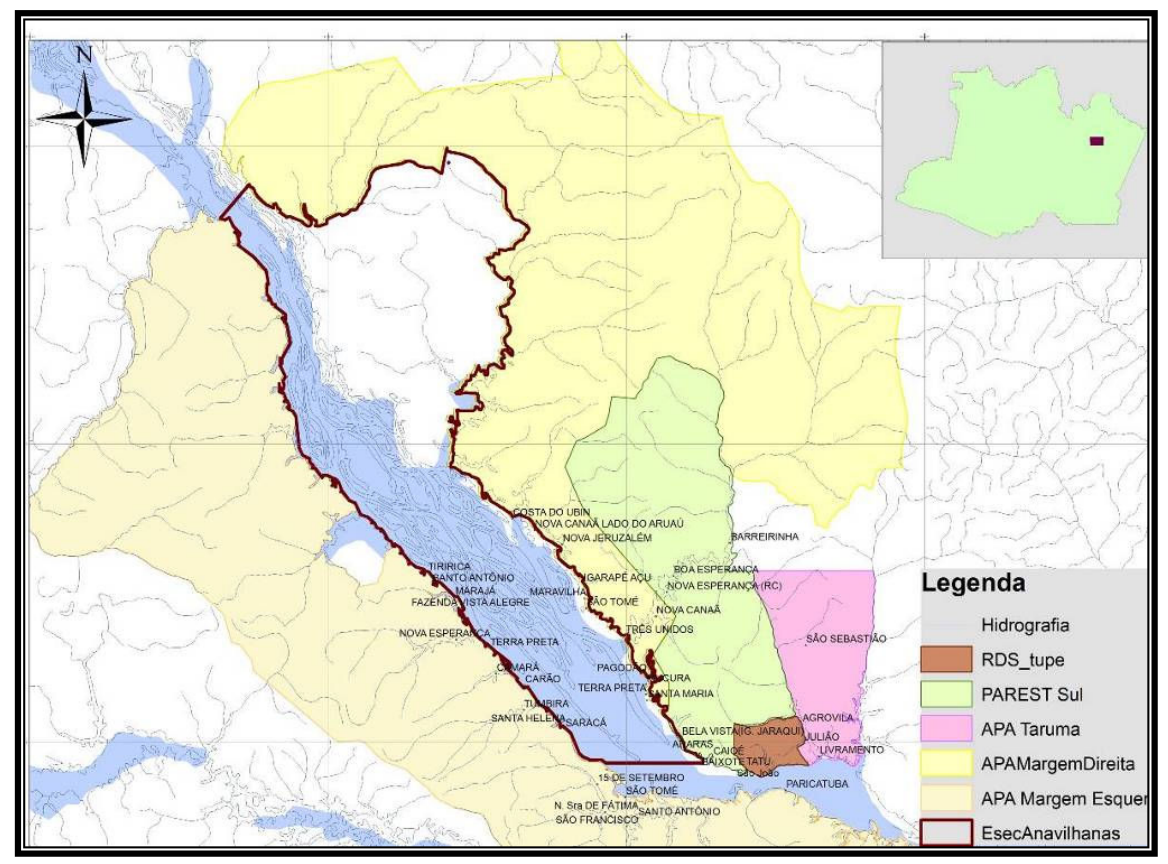

FIGURA 2: Comunidades visitadas frequentemente por barcos de turistas.

\section{Métodos}

Nos locais onde atua, o IPÊ tem adotado um modelo de conservação próprio (Figura 3 ), desenvolvido com base nas experiências obtidas com os anos de trabalho. É um modelo de ação integrado que inclui pesquisa de espécies ameaçadas, educação ambiental, restauração de habitats, envolvimento comunitário e desenvolvimento sustentável, conservação da paisagem e envolvimento em políticas públicas. Um dos objetivos do IPÊ é conservar a biodiversidade respeitando as tradições das comunidades do entorno dos locais que precisam ser protegidos e onde são realizadas suas pesquisas. As alternativas sustentáveis para geração de renda surgem para criar novas fontes de sustento para as famílias destas regiões, o que auxilia na diminuição da pressão humana sobre a biodiversidade local. 


\section{Modelo IPÊ de Conservação}

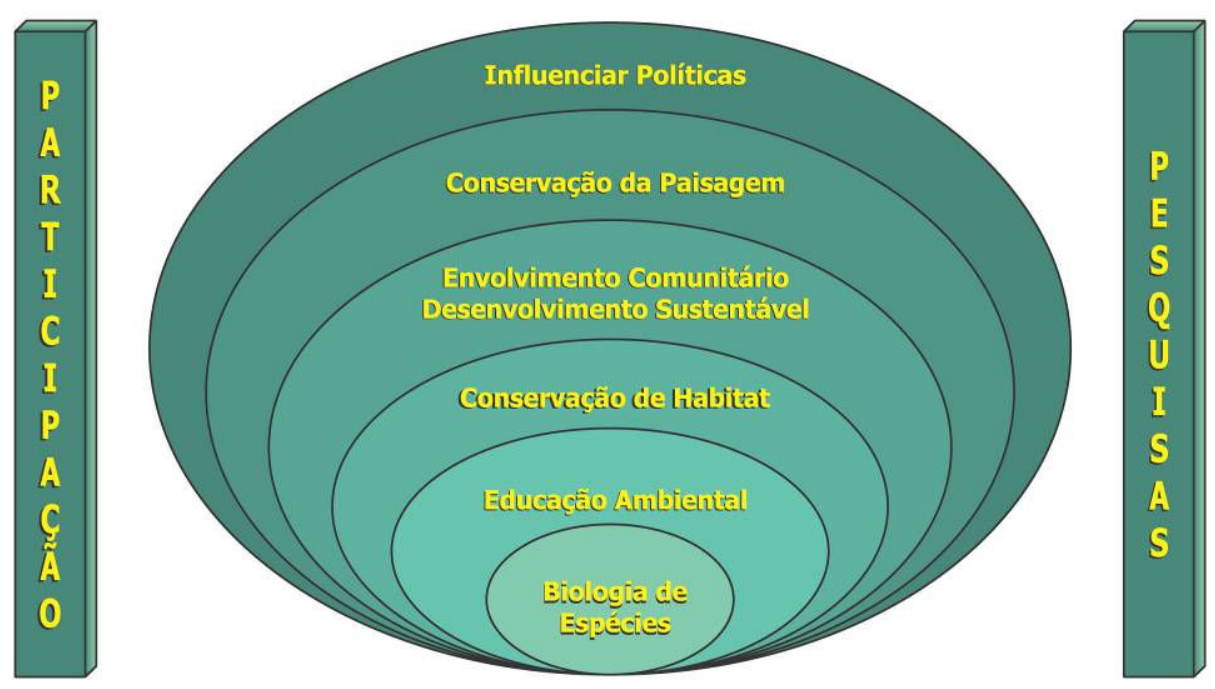

FIGURA 3: Modelo IPÊ de conservação

De forma complementar ao modelo IPÊ, para este trabalho foi aplicada a metodologia proposta por Boo (1993) para planejamento de turismo em áreas protegidas. Esta metodologia foi modificada e adaptada para a realidade amazônica resultando nos seguintes passos:

- Identificar os protagonistas que atuam diretamente e/ou indiretamente no baixo rio Negro com a atividade turística;

- Formar um grupo de trabalho representativo com a responsabilidade de reunirse regularmente e que possibilite formar parcerias com o intuito de consolidar ainda mais o grupo;

- Identificar um cenário desejado de turismo sustentável para esta região;

- Determinar estratégias para se atingir o cenário desejado de turismo sustentável.

Os primeiros encontros possibilitaram identificar os protagonistas atuantes na região. Foram levantados três grupos principais: populações residentes nas margens do rio Negro, gestores governamentais de meio ambiente e turismo e, por fim, o trade turístico. O próximo passo foi selecionar os interessados, em cada grupo, que pudessem representá-lo.

- Guias de turismo: a maioria freelance que trabalham com duas ou mais agencias e/ou barcos de turismo;

- Canoeiros de Novo Airão: a maioria freelance onde muitos trabalham com canoas própria; 
- Membros das comunidades: há aproximadamente 50 comunidades cujo acesso é principalmente fluvial; muitos deles trabalham com turismo;

- Setor Público de Turismo - Empresa Estadual de Turismo (Amazonastur) e Fundação Municipal de Cultura e Turismo (Manaustur atualmente Manauscult);

- Setor Público de Meio Ambiente - IBAMA (atualmente o responsável pelas unidades de conservação é o Instituto Chico Mendes de Conservação da Biodiversidade (ICMBio), Secretaria de Meio Ambiente e Desenvolvimento Sustentável do Estado do Amazonas (SDS), Centro Estadual de Unidades de Conservação (CEUC) e Secretaria Municipal de Meio Ambiente e Sustentabilidade (SEMMAS);

- Trade turístico - agências de turismo, associações como: Associação de Operadores de Barcos de Turismo (AOBT), Associação Brasileira de Agencias de Viagem (ABAV), atualmente participa a Associação de hotéis de selva, Associação de turismo de Novo Airão (ATUNA), Associação Novo Airense de Turismo (ANATUR) e Associação Brasileira de Ecoturismo e Turismo de Aventura (ABETA);

- Serviço Brasileiro de Apoio às Micro e Pequenas Empresas (SEBRAE).

Depois de identificados foi formado um grupo de trabalho representativo para participar das reuniões de planejamento participativo. Segundo Molina (2001), o planejamento participativo contribui para a diminuição de conflitos, atende de maneira abrangente todos os envolvidos no processo e o plano surge como um produto da sociedade como um todo e não somente dos planejadores. Baseado neste conceito verificou-se a importância de melhorar a comunicação entre os principais protagonistas e a necessidade de haver encontros frequentes a fim de planejar, em parceria, as ações futuras para a atividade. Esta experiência em busca de um modelo turístico integrado e planejado com os diferentes protagonistas foi apontada por Bartholo (2009), como uma experiência brasileira de turismo de base comunitária.

Nos primeiro encontros foram selecionadas quatro questões que norteariam o dialogo, seguindo os critérios do planejamento participativo:

1. Será que os representantes dos três grupos têm conhecimento sobre o conceito de unidade de conservação segundo as normas e diretrizes do SNUC (Sistema Nacional de Unidades de Conservação) e SEUC (Sistema Estadual de Unidades de Conservação do Amazonas)?

2. Como realizar visitação na Estação Ecológica de Anavilhanas apesar das limitações impostas pela sua categoria de manejo?

3. Será que as populações ribeirinhas estão se beneficiando da atividade turística realizada atualmente no entorno da ESEC Anavilhanas?

4. Como tornar o turismo nesta região numa atividade realmente sustentável? 


\section{A participação das comunidades ribeirinhas}

Dos três grupos identificados, as comunidades localizadas nas margens do rio Negro foi o primeiro a ser envolvido. Desde o início da atuação do IPÊ na Amazônia o planejamento das ações previa a participação dos ribeirinhos, seguindo o modelo de conservação institucional. Desta forma, quando a proposta de ordenamento do turismo teve início, as comunidades já participavam dos projetos de pesquisa com fauna e educação ambiental.

Em 2003 foram realizadas três oficinas com a participação de 25 líderes das comunidades localizadas na margem esquerda de rio Negro (Figura 4). O objetivo foi capacitá-los sobre o tema unidades de conservação e as diferentes características de suas categorias de manejo, pois constatou-se que apesar destas comunidades estarem localizadas dentro ou no entorno das UCs e esta condição afetar diretamente a vida de seus moradores, a grande maioria desconhecia o assunto. Participaram destas oficinas gestores das unidades de conservação das três esferas governamentais (Instituto Brasileiro de Meio Ambiente e Desenvolvimento Sustentável - IBAMA, Secretaria de Desenvolvimento Sustentável do Estado do Amazonas - SDS, Instituto de Proteção Ambiental do Amazonas - IPAAM e a Secretaria de Meio Ambiente do Município de Manaus - SEMMA), gestores de turismo (Empresa Amazonense de Turismo Amazonastur e Fundação Municipal de Turismo - Manaustur) e o trade turístico.

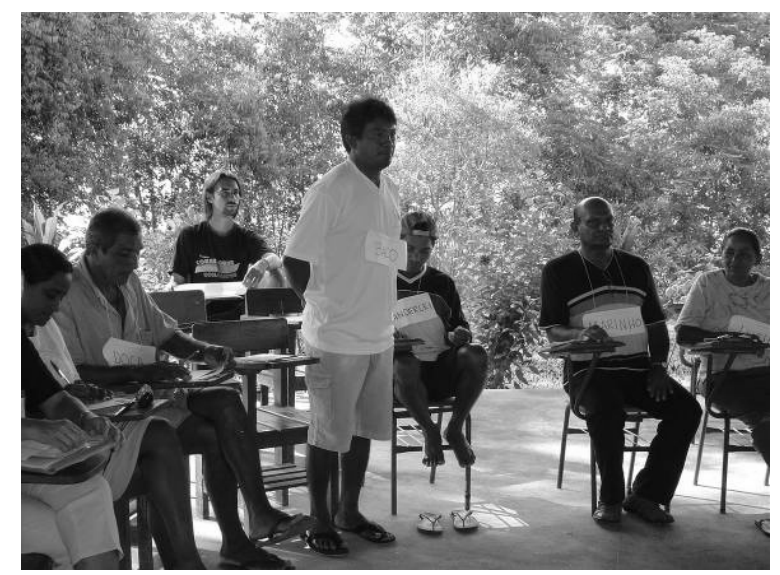

Figura 4: Oficina para capacitação de lideranças comunitárias;

Em 2004, durante as atividades de campo, percebeu-se que a maioria dos lideres comunitários que participavam das oficinas não compartilhavam as informações recebidas com outros membros de suas comunidades - uma forma de propagar conhecimento fundamental na Amazônia em função das grandes distâncias e dificuldades de deslocamento. Assim, optou-se por realizar capacitações direcionadas às lideranças comunitárias desenvolvendo o tema "liderança efetiva e eficiente". Participaram desta capacitação os líderes comunitários já empossados e os potenciais, como estratégia de envolver mais pessoas com perfil adequado a esta função.

Entre os resultados obtidos nas reuniões participativas, a necessidade de desenvolver alternativas sustentáveis de renda ligada ao turismo foi evidenciada. Os 
produtos artesanais da região tinham pouca variedade e utilizavam quase sempre as mesmas espécies de madeira e sementes, o que coloca em risco a conservação da floresta. Apesar de algumas comunidades já receberem turistas, praticamente nenhum produto alimentício baseado no conhecimento local era oferecido. Desta forma, a coordenação deste projeto uniu-se aos pesquisadores do programa de agrobiodiversidade do IPÉ - que já atuavam na região - para desenvolver oficinas e apoiar a produção artesanal sustentável, com abordagens educativas. Estes pesquisadores já vinham coordenando projeto de extensão em meliponicultura associada a sistemas agroflorestais (Figura 5). Houve também um intercâmbio entre mulheres de diferentes comunidades para troca de informações: aprender a produzir doces, geleias e compotas com frutas locais e também como embalar e calcular preço dos produtos.

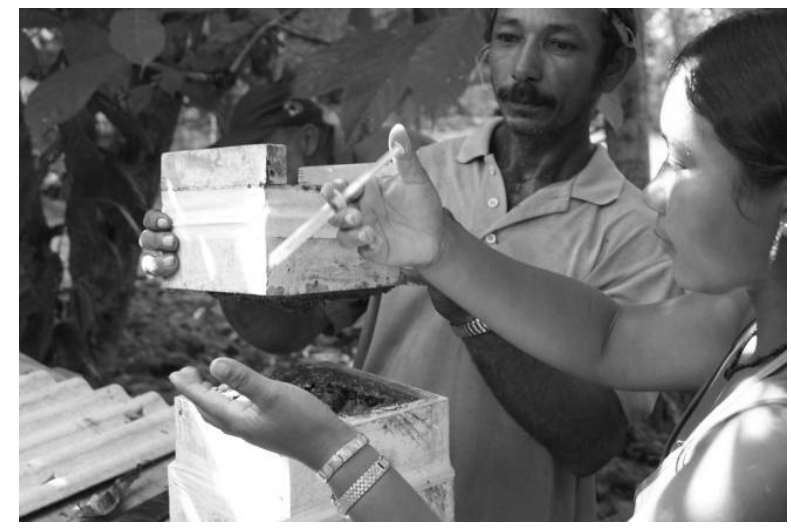

Figura 5: Produção de mel de abelhas nativas

\section{Trade Turístico e Gestores Públicos integrados}

Com as comunidades envolvidas e participantes, partiu-se para envolver o trade turístico. Em 2005, foi decidido iniciar os contatos por Manaus. O primeiro grupo a ser chamado a participar foi o dos canoeiros, que atua de maneira informal no porto de Manaus, e que na maioria das vezes não participava das reuniões de planejamento. Estes profissionais trabalham com pequenas canoas de alumínio e motor de pequeno e médio porte. O turista de menor poder aquisitivo, ou que deseja vivenciar roteiros alternativos fora dos grandes grupos de turistas que participam dos roteiros mais tradicionais, contratam estes canoeiros diretamente no porto de Manaus e invariavelmente se dirigem a região do rio Negro sem nenhuma preparação e/ou planejamento prévio.

Naquele momento, seguindo a metodologia proposta para o projeto, iniciou-se a formação do grupo de trabalho que representasse se não todos, pelo menos a maioria dos grupos envolvidos com as atividades turísticas no baixo rio Negro. Este grupo tinha como principais funções identificar o cenário desejado de turismo sustentável para esta região e determinar estratégias para se atingir o cenário desejado. Inicialmente, as instituições representadas foram: Amazonastur, Manaustur, IBAMA, SDS/IPAAM, SEMMA, Associação dos Operadores de Barcos de Turismo do Amazonas - AOBT e Associação Brasileira de Agencias de Viagens- ABAV, com apoio do SEBRAE (Figuras 6 e 7). 

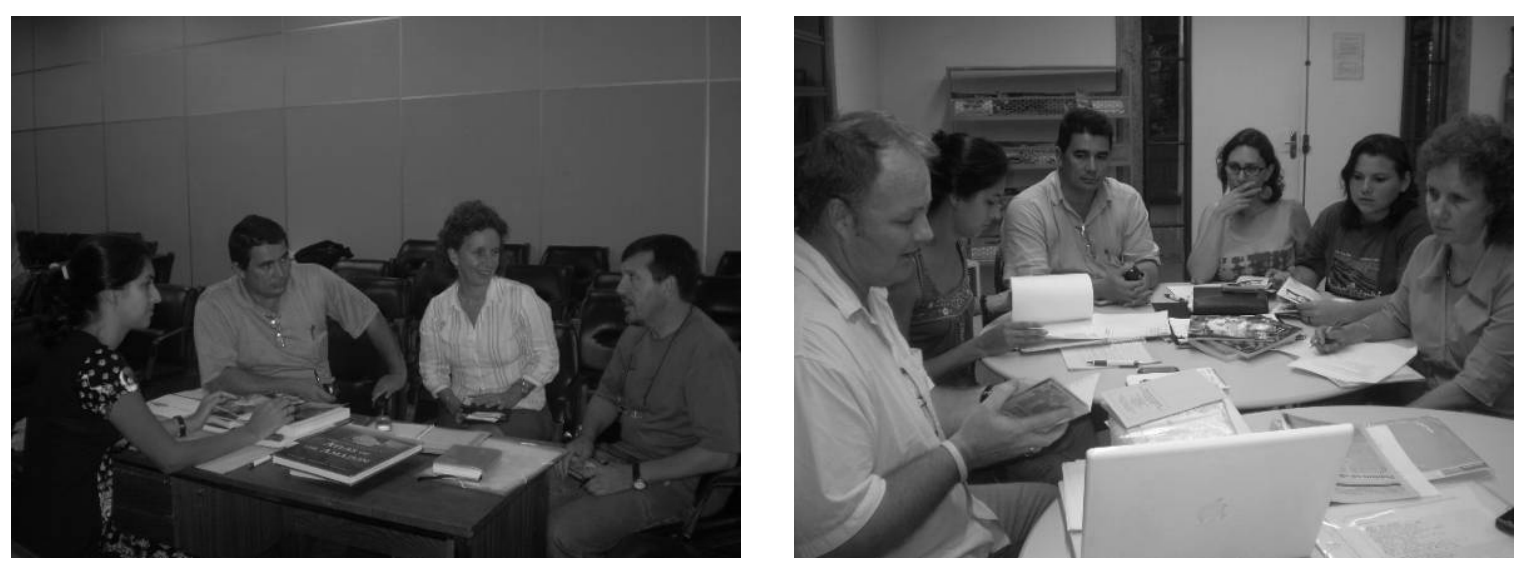

Figuras 6 e 7: Reunião com o Grupo de trabalho de ordenamento do turismo no BRN.

As primeiras oficinas tiveram caráter informativo, onde se debateu com os participantes conceitos sobre unidades de conservação e relacionando-os ao turismo (Fotos 8 e 9 ). Estas atividades se tornaram contínuas, fortalecendo o entendimento entre as instituições públicas, os agentes de turismo e a sociedade civil organizada em busca do ordenamento do turismo na região. Também foram mapeadas as comunidades utilizadas pelos representantes do trade para condução dos turistas. Havia grande rotatividade na escolha destas comunidades em função de critérios comerciais que não levavam em conta conceitos de sustentabilidade socioambientais, gerando expectativas não atendidas e frustrações. Este era um grande desafio a ser superado.
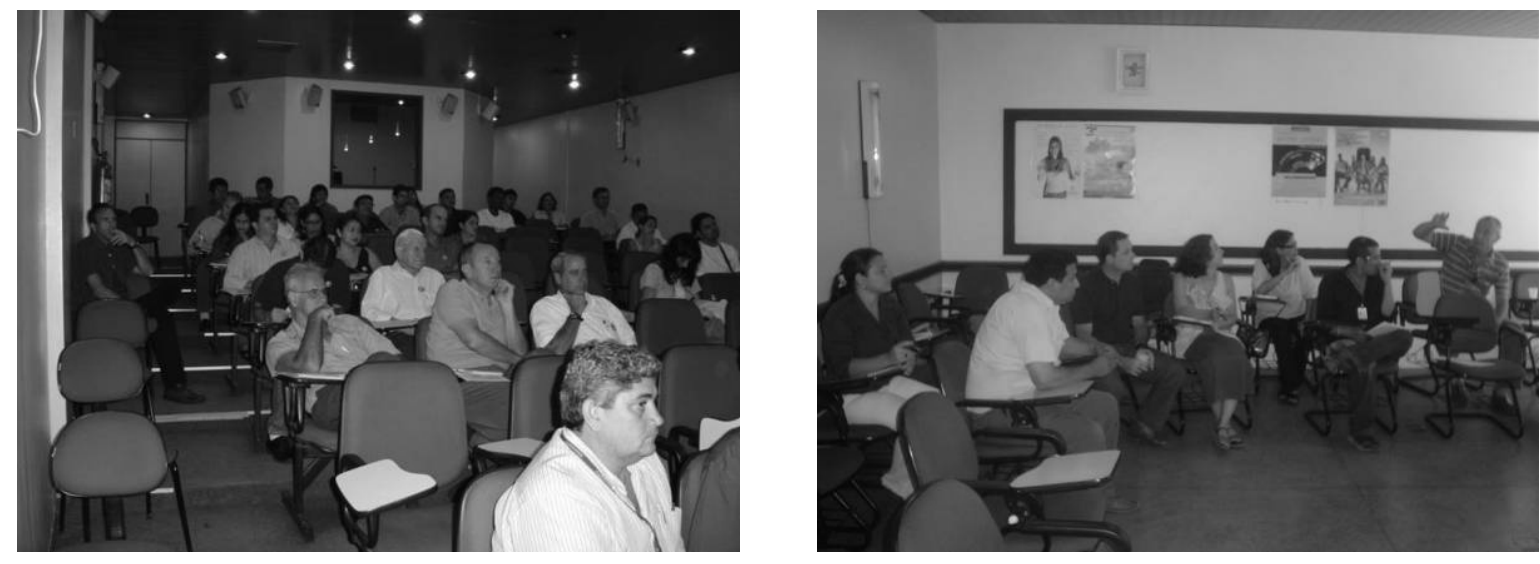

Figuras 8 e 9: Oficinas com o Trade Turístico e Instituições de Turismo e Meio Ambiente

Com base nestas informações ficou estabelecida a necessidade de conhecer com mais profundidade as diferentes visões dos participantes em relação ao turismo na região. Para tanto, decidiu-se aplicar o método de planejamento denominado FOFA - Fortalezas, Oportunidades, Fraquezas e Ameaças. Este método integra todas as informações disponíveis e as categoriza em quatro grupos, facilitando a visão geral do processo e o planejamento das ações futuras. Os resultados desta oficina de planejamento indicaram: a necessidade de mais capacitações com informações sobre o bai- 
xo rio Negro; incluir a interpretação ambiental como ferramenta de trabalho para as ações nas UCs; elaborar um código de conduta para a visitação nas unidades de conservação e comunidades da região; e também produzir uma cartilha para trabalhar os temas anteriores com as populações ribeirinhas da região.

O código de conduta consciente para a visitação das unidades de conservação do baixo rio Negro foi uma das primeiras ações realizadas. Este era um dos principais anseios dos gestores das Unidades de Conservação, principalmente da então Estação Ecológica de Anavilhanas. Esta categoria de UC só permite, segundo o Sistema Nacional de Unidades de Conservação, visitação de caráter educativo. E no Plano de Manejo ${ }^{3}$ desta unidade também estava estabelecida a visitação educativa como uma alternativa de manejo coerente e necessária. No entanto, seria preciso definir o que poderia ser este tipo de visitação e como adequá-lo à realidade da região e também às necessidades profissionais do trade.

Concomitantemente aos encontros para a produção do código de conduta, iniciou-se a elaboração da cartilha. Esse material foi direcionado aos membros das comunidades com linguagem e ilustrações apropriadas.

\section{O importante elo formado pelos guias e condutores de turismo}

No final de 2007 começou a capacitação direcionada aos guias e condutores de turismo. Esses profissionais têm grande importância, pois representam o elo entre os vários atores que participam das atividades turísticas. Aquele era o momento para integrá-los definitivamente ao processo e fornece-lhes uma preciosa ferramenta de trabalho: a interpretação ambiental, pois por meio dela é possível facilitar o conhecimento e a apreciação da natureza de maneira interativa. O curso tinha a duração de três dias, sendo que o último dia era totalmente indicado a atividades práticas que eram realizadas nas UCs do baixo rio Negro (Figuras 10 e 11). O conteúdo do curso está descrito no Quadro 1.
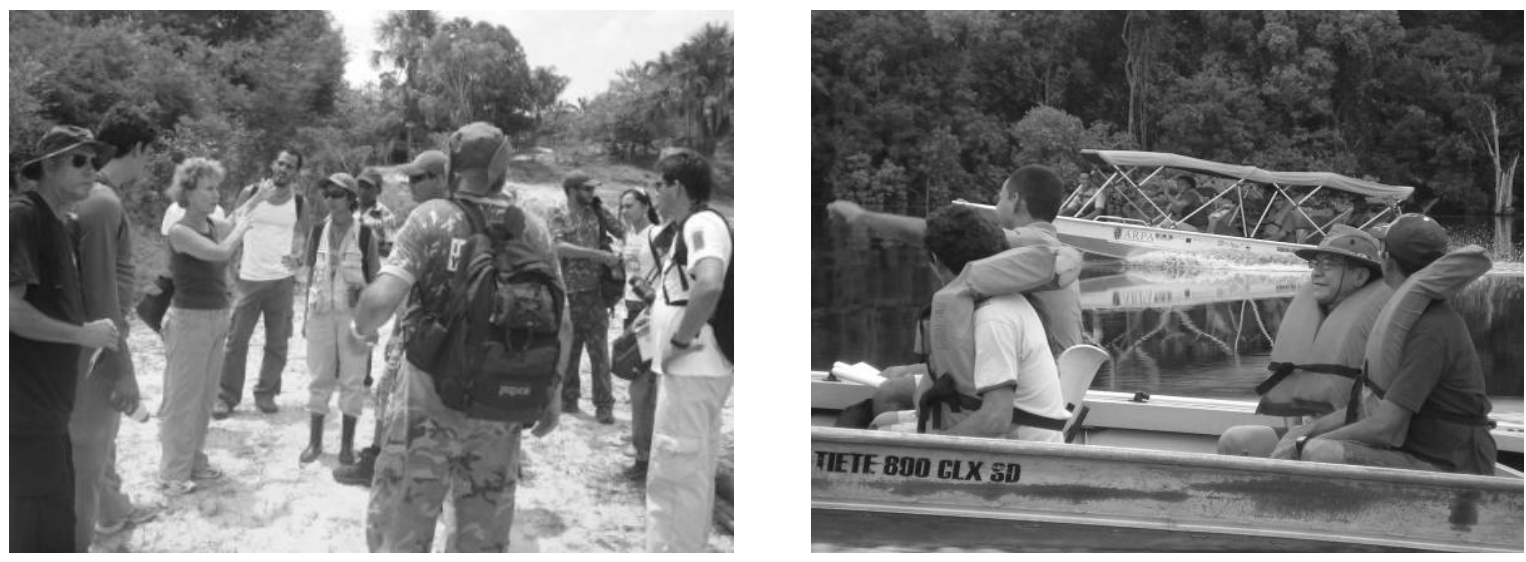

Figuras 10 e 11: Aula prática de interpretação ambiental 
QUADRO 01: Conteúdo da capacitação para guias e condutores de turismo atuantes no baixo rio Negro.

\begin{tabular}{|c|c|c|c|}
\hline DIA & HORAS & OBJETIVOS & CONTEÚDO PROGRAMÁTICO \\
\hline 1 & 08 hs & $\begin{array}{l}\text { - Identificar as unidades de conserva- } \\
\text { ção do baixo rio Negro } \\
\text { - Conhecer o que é permitido e o que } \\
\text { não é permitido em cada categoria de } \\
\text { manejo } \\
\text { - Demonstrar conhecimento básico } \\
\text { sobre plano de manejo e plano de } \\
\text { uso público }\end{array}$ & $\begin{array}{l}\text { UNIDADE I } \\
\text { 1.1 Localizações das UCs em mapa } \\
\text { 1.2 As categorias das unidades de conser- } \\
\text { vação } \\
\text { 1.3 As três esferas de gestão governamen- } \\
\text { tais: ICMBio, SDS/IPAAM, SEMMA } \\
\text { 1.4 Plano de manejo } \\
\text { 1.5 Plano de uso público }\end{array}$ \\
\hline DIA & HORAS & OBJETIVOS & CONTEÚDO PROGRAMÁTICO \\
\hline 2 & 08 hs & $\begin{array}{l}\text { - Entender a utilização de interpreta- } \\
\text { ção no papel da conservação } \\
\text { - Compreender os conceitos funda- } \\
\text { mentais da interpretação }\end{array}$ & $\begin{array}{l}\text { UNIDADE II } \\
\text { 2.1 Objetivos de interpretação } \\
2.3 \text { Suas práticas } \\
\text { 2.4 Relação entre interpretação e conserva- } \\
\text { ção } \\
2.5 \text { Características da interpretação } \\
2.6 \text { Guia intérprete } \\
\text { 2.7 Preparação e material }\end{array}$ \\
\hline DIA & HORAS & OBJETIVOS & CONTEÚDO PROGRAMÁTICO \\
\hline 3 & 08 hs & $\begin{array}{l}\text { - Praticar interpretação ambiental } \\
\text { dentro de uma unidade de conserva- } \\
\text { ção }\end{array}$ & $\begin{array}{l}\text { UNIDADE III } \\
\text { 3.1 Empregando interpretação ambiental } \\
\text { 3.2 Trilhas, comunidade e água }\end{array}$ \\
\hline
\end{tabular}

Em março 2008 foi realizado o primeiro curso financiado pelo Programa ARPA - Áreas Protegidas da Amazônia ${ }^{4}$, em parceria com gestores do Parque Nacional de Anavilhanas. Foram realizados três cursos para guias de turismo de Manaus e um para os canoeiros de Novo Airão. Vale ressaltar que alguns dos instrutores dos cursos eram os próprios gestores das UCs, o que possibilitava uma aproximação destes com os guias de turismo.

Ao final de cada curso foi aplicado um questionário de avaliação. Alguns dos participantes mencionaram que gostariam de receber mais informações técnicas sobre o baixo rio Negro. Baseado nisso duas palestras foram realizadas. Uma delas numa embarcação cedida por um dos integrantes do grupo de trabalho e outra nas dependências do Centro Universitário do Norte, com a participação dos graduandos em 
turismo. Esta estratégia integrava cada vez mais outros atores no processo de ordenamento do turismo e nas discussões sobre a sustentabilidade de todo o processo.

Atualmente, o grupo de trabalho está envolvido nas adaptações necessárias à visitação pública que a alteração de categoria de manejo de Anavilhanas - de Estação Ecológica para Parque Nacional - possibilitou. Está sendo elaborado um plano de uso público emergencial enquanto o plano de manejo não é revisado, com o objetivo de evitar impactos de uma possível visitação em larga escala.

\section{Resultados e discussão}

Nos últimos anos as atividades turísticas na região do baixo rio Negro têm se intensificado com um aumento significativo no número de turistas embarcados e construções de alojamentos de selva. Como resultado das oficinas e capacitações realizadas até o momento podemos notar que o trade turístico tem internalizado os conhecimentos adquiridos. Isto os têm colocado na posição de aliados da conservação e, segundo Drumm e Moore (2002), esta condição é vantajosa já que o êxito de seu produto depende em parte da qualidade do meio ambiente. As capacitações beneficiaram também a maioria dos guias e condutores de turismo que atuam no baixo rio Negro, fazendo-os sentir-se mais seguros na condução do seu trabalho. Pesquisadores e técnicos de institutos de pesquisa contribuíram com esta capacitação. Tanto Pereira (2007) quanto Romagnoli (2009) enfatizam que o emprego da técnica de interpretação ambiental enriqueceria a experiência das visitantes. Após as capacitações estes profissionais estão começando a utilizar esta técnica melhorando a qualidade de seus serviços.

Ceballos-Lascuráin (1996) enfatiza que para o turismo tornar-se sustentável é necessário melhorar os elos entre conservação, comunidades e a indústria de turismo. Também sugere que se adote uma abordagem integrada do tripé de sustentabilidade envolvendo as instituições públicas federais, regionais e locais. O mesmo autor reconhece, contudo, que muitas vezes os interesses do turismo não estão integrados com os de outros ministérios, como por exemplo, o de meio ambiente. Pereira (2007) comenta que para seu êxito, o turismo sustentável deve ser uma prioridade do governo em todas as repartições. No que diz respeito ao baixo rio Negro, a formação do grupo resultou ainda em outras ações que incentivaram os gestores públicos a conseguir recursos para dotar as unidades de conservação de alguns instrumentos de gestão, como: Plano de Manejo para o Parque Estadual do Rio Negro setores Norte e Sul, e Parque Nacional do Jaú; Plano de Uso Público para a RDS Tupé (SEMMA, 2007) e para o Parque Nacional do Jaú (Aubreton, 2002); um Plano Emergencial de Uso Público que está sendo elaborado para o Parque Nacional de Anavilhanas; e um Plano de Negócios para o turismo no Parque Estadual do Rio Negro setor Sul (IPÊ, 2006). Esses documentos são de grande importância para o planejamento da visitação nestas unidades de conservação.

Drumm e Moore (2002) apontam o importante papel que as ONGs desempenham como facilitadoras nas ações de planejamento. Podemos ver isto claramente no 
trabalho que o IPÊ vem desenvolvendo, incentivando o fortalecimento de parcerias através do dialogo, coordenando oficinas e, às vezes, captando recursos financeiros para poder realizá-las. Isto ocorreu com este trabalho que teve apoio financeiro durante todo seu desenvolvimento do Programa de Meio Ambiente da USAID-Brasil ${ }^{5}$, através do Forest Enterprise Cluster. Ceballos-Lascuráin (1996) enfatiza, também, que as ONGs podem criar parcerias com empresas de turismo privadas e/ou com comunidades.

Ceballos-Lascuráin (1996) menciona que as comunidades localizadas no entorno das Unidades de Conservação muitas vezes são esquecidas no planejamento de turismo nestas áreas. Diz ainda ser muito importante envolve-los, pois na maioria das vezes estas populações são as mais afetadas pela atividade que está sendo planejada. Neste sentido o IPÊ, em conjunto com os gestores das UCs, tomou a iniciativa de trabalhar junto com as comunidades, realizando oficinas esclarecedoras e elaborando uma cartilha de interpretação ambiental. Com essas iniciativas mais as atividades de educação ambiental e agroflorestal as comunidades estão cada vez mais preparadas para participar do planejamento do turismo sustentável para a região.

A experiência de parcerias ao longo dos anos confirma que Drumm e Moore (2003) estão corretos quando explicam que a chave de sucesso é a formação de sólidas parcerias, de modo que múltiplos objetivos de conservação e desenvolvimento equitativo possam ser alcançados. Podemos ver claramente que os protagonistas envolvidos se uniram para trabalhar para o desenvolvimento da região, melhorando o turismo e ao mesmo tempo conservando o meio ambiente, e empoderando as comunidades envolvidas em todas as fases deste processo.

\section{Conclusão}

Os resultados obtidos demonstram que a capacitação e integração dos protagonistas por meio de reuniões, oficinas e cursos de interpretação ambiental foram de grande importância para o desenvolvimento da atividade turística local. Foram criados espaços para debates, discussões, construções de caminhos e ideias em prol de um objetivo comum: conservar o ambiente natural da região e beneficiar-se dele de forma sustentável, buscando sempre estar de acordo com as diretrizes que regem o espaço territorial protegido.

Os desafios a serem alcançados ainda são grandes. É necessário conseguir o comprometimento das instituições públicas independentemente das mudanças cíclicas dos seus quadros técnicos. É fundamental envolver as comunidades de maneira justa em todas as fases do processo, tanto na prestação de serviços como no planejamento das atividades. $E$ os integrantes do trade turístico devem assumir que não é possível executar suas atividades profissionais desconsiderando questões de conservação socioambiental, pois isto liquidaria seu negócio. O cenário esperado a longo prazo é o ordenamento da atividade turística de maneira sustentável e que esta prática seja incorporada por todos os protagonistas que atuam no baixo rio Negro. 


\section{Referências Bibliográficas}

AUBRETON, T. Plano de Uso Público para o Parque Nacional do Jaú. Manaus: Ibama/MMA PROECOTUR, 2002.

BADIALLI, J.E.L. O Reverso do Postal: uma análise das atividades de uso público na região da Estação Ecológica de Anavilhanas, Estado do Amazonas, Brasil. Dissertação de Mestrado em Tecnologias para a Sustentabilidade na Amazônia. Manaus: Universidade Federal do Amazonas, 2003.

BARTHOLO, R.; Sansolo, D. G.; Bursztyn. Turismo de base Comunitária: diversidade de olhares e experiências brasileiras. Rio de Janeiro: Letra e Imagem, 2009.

BOO, E. Ecotourism Planning for Protected Areas In: LINDBERG, K.; HAWKINS, D. Ecotourism: A guide for Planners and Managers. Vermont, USA: The Ecotourism Society, 1993.

BRASIL. MMA. Biodiversidade brasileira: avaliação e identificação de áreas e ações prioritárias para conservação, utilização sustentável e repartição de benefícios da biodiversidade nos biomas brasileiros. Brasília: MMA, 2002.

CEBALLOS-LASCURAIN, H. Tourism, Ecotourism and Protected Areas. Suíça: IUCN, 1996.

DIAS, R. Turismo Sustentável e Meio Ambiente. São Paulo: Atlas, 2008.

DRUMM, A.; MOORE, A. Desenvolvimento do Ecoturismo, um manual para os profissionais de conservação. Virginia: The Nature Conservancy. 2003

IPÊ-Instituto de Pesquisas Ecológicas. Plano de Negócios PERN Setor Sul. Manaus. 2006.

IPÊ - Instituto de Pesquisas Ecológicas. Como Receber Turistas em Áreas Naturais. Manaus: GTZ/Projeto Corredores Ecológicos. 2008.

KINKER, S. Ecoturismo e Conservação da Natureza em Parques Nacionais. Campinas, S.P: Papirus, 2002.

MOLINA E., S.; RODRÍGUEZ A., S. Planejamento integral do turismo: um enfoque para a América Latina. Bauru ( SP): EDUSC, 2001.

NELSON, S.; PEREIRA, E. Ecoturismo, práticas para turismo sustentável. Manaus: Valer, 2004.

PEREIRA, E. M.. From Extraction to Attraction: Making Ecotourism a Reality in the Municipality of Manaus, Amazonas, Brazil. Doctoral Dissertation, Faculty of Social Sciences, University of Stavanger. Norway, 2007. 
ROMAGNOLI, F. C. 2009. Interpretação ambiental e envolvimento comunitário: ecoturismo como ferramenta para a conservação do boto-vermelho, Inia geoffrensis. Dissertação de mestrado, Instituto Nacional de Pesquisas da Amazônia, Manaus: 2009.

SEMMA. Plano de Uso Público do Tupé. Manaus, 2007.

SNUC, 2000. Sistema Nacional de Unidades de Conservação. Ministério do Meio Ambiente. Brasília(DF), 2000.

WWF Brasil. Manual de Ecoturismo de Base Comunitária, ferramentas para um planejamento responsável. 2003.

\section{Agradecimentos}

Queremos agradecer a todos os participantes e parceiros que se juntaram a nós neste projeto e, em especial, aos apoiadores financeiros Projeto Corredores Ecológicos/ Corredor Central da Amazônia do Ministério do Meio Ambiente, e também a USAID-Brasil através de seu Programa de Meio Ambiente. Sem estas parcerias e apoios este trabalho não teria sido realizado.

\section{NOTAS:}

${ }^{1}$ Criado em 1992, o IPÊ é uma organização da sociedade civil de interesse público que trabalha para a conservação da biodiversidade e o desenvolvimento sócioeconômico de comunidades residentes em áreas prioritárias à conservação dos recursos naturais em diversos ecossistemas do Brasil.

${ }^{2}$ Trade turístico é o conjunto de empresas e profissionais que desenvolvem atividades diretamente ligadas ao turismo.

${ }^{3}$ Documento elaborado para a gestão das unidades de conservação composto por diagnóstico técnico, zoneamento e planejamento através de programas de apoio a gestão destas áreas.

${ }^{4} \mathrm{O}$ ARPA é um programa do Governo Federal, com duração prevista de dez anos, para expandir, consolidar e manter uma parte das unidades de conservação no Bioma Amazônia. Ele é fruto de uma parceria entre o MMA, o ICMBio, governos estaduais e municipais da Amazônia, o Fundo para o Meio Ambiente Global (GEF), o Banco Mundial, o KfW (banco de cooperação do governo da Alemanha), a GTZ (agência de cooperação da Alemanha), o WWF-Brasil, o Fundo Brasileiro para a Biodiversidade (Funbio), e organizações da sociedade civil.

${ }^{5}$ Agência de cooperação do governo dos Estados Unidos da América que apóia o desenvolvimento sustentável nas áreas de saúde e meio ambiente. 
Nailza Pereira Souza: Turismóloga, Pesquisadora do IPÊ - Instituto de Pesquisas Ecológicas em Manaus.

Email: nailza@ipe.org.br

Sherre Prince Nelson: Geóloga, MSc em Educação Ambiental, Professora do Curso de Turismo na Uninorte Manaus e Pesquisadora Associada do IPÊ.

Email: spnelson@ipe.org.br

José Eduardo Lozano Badialli: Engenheiro Agrônomo, MSc em Ciências do Ambiente e Sustentabilidade da Amazônia, Pesquisador do IPÊ em Manaus.

Email: edubadi@ipe.org.br

Link para o currículo Lattes: http://lattes.cnpq.br/9613966168723261

Marco Antônio Vaz de Lima: Técnico Agroflorestal, Pesquisador do IPÊ em Manaus Email: marcoantonio@ipe.org.br

Suzana Machado Padua: Escola Superior de Conservação Ambiental e Sustentabilidade. Educadora Ambiental, PhD, Pesquisadora e Diretora do IPÊ.

Email suzana@ipe.org.br

Link para o currículo Lattes: http://lattes.cnpq.br/0615879056028445

Data de submissão: 29 de outubro 2009.

Data do aceite: 12 de março de 2010. 